\title{
Impact of enhanced personal protective equipment on colonoscopy performance during the COVID-19 pandemic
}

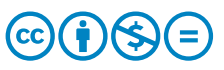

\begin{abstract}
Authors
Kevin Kim Jun Teh, Shu Wen Tay, Kaina Chen, Samantha Jingyun Koh, Yu Jun Wong, Andrew Boon Eu Kwek, James Weiquan Li, Kwong Ming Fock, Eng Kiong Teo, Tiing Leong Ang, Malcolm Teck Kiang Tan
\end{abstract}

Institution

Department of Gastroenterology and Hepatology, Changi General Hospital, Singapore

submitted 21.4.2020

accepted after revision 27.4.2020

Bibliography

DOI https://doi.org/10.1055/a-1167-1703 |

Endoscopy International Open 2020; 08: E809-E814

(c) Georg Thieme Verlag KG Stuttgart · New York

eISSN 2196-9736

Corresponding author

Malcolm Teck Kiang Tan, Department of Gastroenterology and Hepatology, Changi General Hospital, 2 Simei Street 3, Singapore 529889

Fax: +6562830402

malcolm.tan.t.k@singhealth.com.sg

\section{ABSTRACT}

Background and study aims Using personal protective equipment (PPE) can reduce risk of disease transmission. During the COVID-19 pandemic, enhanced PPE (EPPE) is re- commended when performing endoscopy. We aimed to evaluate the impact of EPPE on colonoscopy performance when compared to standard PPE (SPPE).

Patients and methods A review of electronic medical records and endoscopy reports of consecutive patients who underwent colonoscopy during two similar one-month time periods (in 2019 and during the COVID-19 pandemic in 2020) was performed. SPPE was used in 2019 and EPPE was used in 2020. Patient clinical data and procedure-related information were captured and analyzed. The primary outcomes were time to cecum (TTC) and total procedure time. Secondary outcomes were adenoma detection rate (ADR), polyp detection rate (PDR) and cecal intubation rate (CIR). Statistical analysis was performed using STATA v16.1.

Results Two hundred and forty-seven colonoscopy procedures were analyzed. Baseline demographics and indications for colonoscopy of patients in both groups were similar. There were no significant differences in median TTC ( 10.0 vs $10.0 \mathrm{~min}, P=0.524$ ) or total procedure time ( 22.5 vs $23.0 \mathrm{~min}, P=0.946$ ) between colonoscopy performed in SPPE and EPPE. The ADR, PDR and CIR were also similar.

Conclusion Our findings suggest that use of EPPE does not affect colonoscopy performance.

\section{Introduction}

During the COVID-19 pandemic, use of enhanced personal protective equipment (EPPE) has been recommended by various professional organizations to reduce the risk of endoscopist exposure and infection during gastrointestinal endoscopy [1-6]. Singapore was one of the first countries after China to be affected by COVID-19 and was also severely affected by the 2003 outbreak of severe acute respiratory syndrome (SARS). In Singapore, the recommended EPPE for both upper and lower gastrointestinal endoscopy during the COVID-19 pandemic consists of N95 filtering face piece (FFP) respirator, face shields, and hairnets, in addition to the standard personal protective equipment (SPPE) of water-resistant gown and gloves [6]. Use of such EPPE for staff protection during the COVID-19 pan- demic was implemented beginning on February 7, 2020. This practice is somewhat different from other recommendations which regarded lower gastrointestinal endoscopy as a procedure with lower risk of disease transmission and only recommended the use of surgical face mask and not N95 mask [14]. In Singapore, more stringent measures were adopted based on our experience with SARS, and the fact that there is ongoing local community transmission, which involved asymptomatic individuals without risk factors for COVID-19 exposure. Both upper and lower gastrointestinal endoscopy procedures require close patient contact, with the possibility of disease transmission [7-9]. Use of such EPPE during endoscopy is in addition to stringently screening patients prior to endoscopy, postponing endoscopy for those deemed at risk of exposure to or infection 
from COVID-19, and limiting elective cases to those that cannot be deferred.

The impact of PPE on healthcare worker performance has been evaluated in other critical care scenarios but not during endoscopy. PPE has been shown to negatively impact fine-motor skills required to perform procedures such as endotracheal intubation and intravenous cannula insertion [10]. FFP respirators result in an array of physiological and psychological effects, with prolonged usage interfering with respiration, thermal equilibrium, and vision [11]. FFP respirators also interfere with inter-professional communication between health care workers [12]. Vision is of paramount importance during colonoscopy, as aspects including visual acuity, peripheral vision, and color detection are crucial for detection of lesions. Because of fogging, FFP respirators and face shields as a result of fogging, can negatively affect vision and possibly impact endoscopy handling and lesion detection [13].

Given that the COVID-19 pandemic may persist for a longer period or even become an endemic infectious disease, use of EPPE may be required in the longer term. The impact it has on colonoscopy quality outcomes is unclear. We aimed to evaluate the impact of EPPE use on the task of performing colonoscopy and related quality outcomes.

\section{Patients and methods}

\section{Study design}

This was an exploratory retrospective, observational study conducted in a single tertiary referral center in Singapore. Formal Institutional Review Board (IRB) approval was not required as per institutional protocol for such a study design. Colonoscopy procedures performed in two similar 4-week time periods February 1 to 28, 2019 and February 7 to March 5, 2020 were evaluated. SPPE was used for endoscopy procedures performed in 2019 and EPPE for endoscopy procedures performed beginning on February 7, 2020.

\section{Patient selection}

A retrospective chart review of electronic medical records and electronic colonoscopy reports of consecutive patients who underwent colonoscopy in the Department of Gastroenterology and Hepatology, Changi General Hospital, Singapore, was performed. Data on patient demographics that influenced colonoscopy performance including body mass index (BMI), medical history, and previous abdominal surgery were reviewed [14]. Indications for colonoscopy, time to cecum (TTC), withdrawal time, total procedure time, cecal intubation rate (CIR), endoscopic findings, and involvement of a trainee in the procedure were collected. We defined an experienced endoscopist as one who has performed more than 500 colonoscopies and a trainee endoscopist as one requiring direct supervision. We included all diagnostic colonoscopies in our final analysis and excluded patients who underwent lower gastrointestinal procedures for endoscopic resection or colonic stenting.

\section{6 colonoscopies performed in total

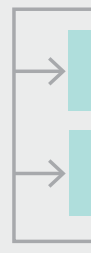 \\ 7 excluded: performed for advanced endoscopic resection (EMR $\left.{ }^{1}, \mathrm{ESD}^{2}\right)$ \\ 2 excluded: performed for stenting of obstructed colonic neoplasm}

247 diagnostic colonoscopies evaluated

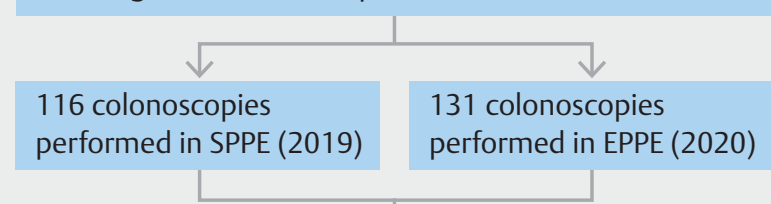

Analysed for:

(1) Time to caecum (TTC), total procedure time

(2) Overall adenoma detection rate, overall polyp detection rate, caecal intubation rate

'EMR - Endoscopic Mucosal Resection

${ }^{2} E S D$ - Endoscopic Submucosal Dissection

- Fig. 1 Study design.

\section{Outcomes}

Our primary outcomes were TTC and total procedure time. These two indices were selected as they best represented the task of performing a colonoscopy and were captured objectively in the electronic reporting system. Secondary outcomes were adenoma detection rate (ADR), polyp detection rate (PDR), and CIR.

\section{Statistical analysis}

Statistical analysis was performed using STATA version 16.1. Descriptive statistics were computed for all variables in frequencies and percentages. Normally distributed continuous variables were presented in mean \pm standard deviation (SD). Non-parametric variables were presented in median \pm interquartile range (IQR) and analyzed using Mann-Whitney test. Categorical data were analyzed using chi-square or Fisher's exact test. Sample size calculation was not performed as this was an exploratory retrospective study and there was no prior data to guide sample size calculation for an equivalence test.

\section{Results}

\section{Baseline demographics}

A total of 256 lower gastrointestinal endoscopies were performed during the study period. Nine procedures with therapeutic intent (endoscopic resection, colonic stenting) were excluded. Of the remaining 247 diagnostic colonoscopies, 116 were done using SPPE and 131 were done using EPPE (• Fig. 1). Mean patient age (SD) was $57.6 \pm 13.9$ years. The majority of patients were Chinese (68.8\%). Mean (SD) of body mass index 
Table 1 Patient demographics.

\begin{tabular}{|c|c|c|c|}
\hline Variables & 2019 (SPPE) & 2020 (EPPE) & $P$ value \\
\hline Number of patients & 116 & 131 & \\
\hline Age (years) & $58.3 \pm 13.5$ & $57.0 \pm 14.3$ & NS \\
\hline \multicolumn{4}{|l|}{ Gender (n,\%) } \\
\hline Male & $55(47.4)$ & $71(54.2)$ & NS \\
\hline Female & $61(52.6)$ & $60(45.8)$ & NS \\
\hline \multicolumn{4}{|l|}{ Race $(n, \%)$} \\
\hline Chinese & $80(69.0)$ & $90(68.7)$ & NS \\
\hline Malay & $24(20.7)$ & $23(17.6)$ & NS \\
\hline Indian & $5(4.3)$ & $10(7.6)$ & NS \\
\hline Others & $7(6.0)$ & $8(6.1)$ & NS \\
\hline $\operatorname{BMI}\left(\mathrm{kg} / \mathrm{m}^{2}\right)$ & $24.1 \pm 4.3$ & $24.8 \pm 4.4$ & NS \\
\hline $\operatorname{CVRF}(\mathrm{n}, \%)$ & $73(62.9)$ & $77(58.8)$ & NS \\
\hline Cardiac disease (n,\%) & $14(12.1)$ & $23(17.6)$ & NS \\
\hline Cerebrovascular disease (n,\%) & $3(2.6)$ & $7(5.3)$ & NS \\
\hline Chronic Kidney disease (n,\%) & $8(6.9)$ & $13(9.9)$ & NS \\
\hline Liver cirrhosis (n,\%) & $3(2.6)$ & $3(2.3)$ & NS \\
\hline $\operatorname{IBD}(n, \%)$ & $4(3.5)$ & $5(3.8)$ & NS \\
\hline History of abdominal surgery (n,\%) & $11(9.5)$ & $19(14.5)$ & NS \\
\hline \multicolumn{4}{|l|}{ Clinical Indication (n, \%) } \\
\hline Change in bowel habit & $26(22.4)$ & $28(21.4)$ & NS \\
\hline Positive fecal occult blood & $5(4.3)$ & $20(15.3)$ & NS \\
\hline Rectal bleeding & $12(10.3)$ & $10(7.6)$ & NS \\
\hline Pain & $22(19.0)$ & $13(9.9)$ & NS \\
\hline Anemia & $24(20.7)$ & $10(7.6)$ & NS \\
\hline Polyp surveillance & $11(9.5)$ & $20(15.3)$ & NS \\
\hline Others $^{1}$ & $16(13.8)$ & $30(22.9)$ & NS \\
\hline Adequate bowel preparation (n, \%) & $112(96.6)$ & $124(94.7)$ & NS \\
\hline \multicolumn{4}{|c|}{$\begin{array}{l}\text { Values are mean } \pm \text { standard deviation or } \mathrm{n}(\%) \\
\text { Adequate bowel preparation is defined as Boston Bowel Prep score } \geq 2 \text { for each colonic segment } \\
\text { SPPE, standard personal protective equipment; EPPE, enhanced personal protective equipment; BMI, body mass index; CVRF, cardiovascular risk factors; } \\
\text { IBD, inflammatory bowel disease; NS, nonsignificant } \\
1 \text { Other indications include evaluation of IBD, abnormal computed tomography scan findings, elevated carcinoembryonic antigen, and loss of weight. }\end{array}$} \\
\hline
\end{tabular}

(BMI) was 24.4 \pm 4.4 ; 30 (12.1\%) had prior abdominal surgery. The most common indications for colonoscopy were change in bowel habits (21.9\%) and abdominal pain (14.2\%). There was no significant difference in patient demographics, comorbidities, ir indications between both groups ( $>$ Table 1 ).

\section{Primary outcomes}

There was no significant difference in median TTC (10.0 vs $10.0 \mathrm{~min}, P=0.524)$ and total procedure time $(22.5$ vs $23.0 \mathrm{~min}$, $P=0.946$ ) between the SPPE and EPPE groups ( $\triangleright$ Table 2 ).

\section{Secondary outcomes}

There was no statistically significant difference in ADR (29.8\% vs $21.6 \%, P=0.141)$ and PDR (50.4\% vs $40.5 \% P=0.120)$ between the EPPE and SPPE groups. CIR (99.2\% vs $100 \%, P=$ $0.346)$ was also similar between the two groups. Cecal intubation was unsuccessful in one patient due to underlying megacoIon ( Table 2). 
- Table 2 Results.

\begin{tabular}{|l|l|l|l|}
\hline Variables & $\mathbf{2 0 1 9}$ (SPPE) & $\mathbf{2 0 2 0}$ (EPPE) & P value \\
\hline Total number of colonoscopies & 116 & 131 \\
\hline Overall adenoma detection rate (\%) & 21.6 & 29.8 & NS \\
\hline Overall polyp detection rate (\%) & 40.5 & 50.4 & NS \\
\hline Cecal intubation rate (\%) & 100 & 99.2 & NS \\
\hline Time to cecum (min) & $10.0(8.0-16.5)$ & $10.0(7.0-15.0)$ & NS \\
\hline Withdrawal time (min) & $10.0(8.0-16.5)$ & $10.0(10.0-18.0)$ & NS \\
\hline Total procedure time (min) & $22.5(20.0-34.5)$ & $23.0(18.0-35.0)$ & NS \\
\hline $\begin{array}{l}\text { Values for endoscopy times are expressed as median (interquartile range) } \\
\text { SPPE, standard personal protective equipment; EPPE, enhanced personal protective equipment; NS, nonsignificant }\end{array}$ \\
\hline
\end{tabular}

\section{Impact of trainee involvement}

A total of 46 (18.6\%) colonoscopies were performed by trainees under direct supervision. There was no significant difference in TTC (16.0 vs $15.0 \mathrm{~min}, P=0.638$ ), total procedure time (34.5 vs $34.0 \mathrm{~min}, P=0.473)$, ADR (33.3\% vs $25.0 \%, P=0.572)$, PDR (72.2\% vs $50.0 \%, P=0.162)$ or CIR ( $100 \%$ vs $95 \%, P=0.336)$ between colonoscopies performed using SPPE and EPPE. For colonoscopies performed by experienced endoscopists alone, rates of ADR (20.0\% vs $31.1 \% P=0.072)$ and PDR (33.7\% vs $51.9 \%$, $P=0.009)$ were higher with use of EPPE compared to SPPE ( Supplementary Table 1).

\section{Discussion}

During the COVID-19 pandemic, depending on the acuity of country-specific healthcare needs and resources, both in terms of manpower and PPE availability, there will be a need to maintain a fine balance between focusing solely on emergency therapeutic endoscopy procedures and performing limited elective procedures that cannot be unduly postponed [4-6]. Regions overwhelmed by the pandemic are in a crisis mode, with resources diverted to meet the needs of those afflicted by COVID-19, and all elective procedures would be cancelled and the available limited resources would be only used for emergency therapeutic procedures. The period from February to March 2020 was a time during which elective semi-urgent procedures could still be performed, and thus provided an opportunity for us to assess the impact of EPPE on the task and outcome of specific endoscopy procedures. We focused on colonoscopy as opposed to upper endoscopy and other endoscopy procedures as they involve well-established indices that serve as surrogate markers for quality outcomes and about which data are captured automatically and hence available for analysis. To our knowledge, this study is the first to evaluate the effects of EPPE on the task of performing colonoscopy.

The physical discomfort to the endoscopist from wearing EPPE is well recognized. There is justifiable concern about the impact on procedure-related quality outcomes. Our study provides reassurance that objective outcome measures such as time to cecal intubation, total procedure time, ADR and PDR are not negatively impacted by use of EPPE compared to SPPE, with results being similar in both groups. In a subgroup analysis, for credentialed endoscopists, the ADR and PDR were actually higher during the period of EPPE use. This could be due to case selection, in terms of the patients undergoing colonoscopy during this time period possibly having a higher likelihood of underlying pathology due to the procedure indication. For instance, there was a greater proportion of patients (although not statistically significant) who were fecal immunochemical test (FIT)-positive during the period of EPPE use, and such patients have colonoscopy performed by a credentialed endoscopist and not by trainees under supervision. We postulate that there are several reasons why there is no negative impact on colonoscopy outcome measures from use of EPPE. Median TTC and total procedure time were short at 10 minutes and 23 minutes, respectively, and all colonoscopy procedures were performed in air-conditioned suites. Endoscopists had the option of temporarily removing FFP respirators between procedures. All endoscopists were mask-fitted and used face shields with anti-fogging properties, reducing the impact of misting on vision and lesion detection. The majority of experienced endoscopists also had experience performing endoscopy in EPPE for patients requiring airborne precautions such as pulmonary tuberculosis, and during the previous SARS outbreak in 2003.

We acknowledge the study limitations. It was retrospective. The sample size was relatively small as we could only study two similar 1-month periods. Nonetheless, the study does provide new insights into a clinically relevant issue. We focused on robust, objective outcome data that were tracked prospectively and electronically captured. We included all colonoscopy procedures performed during the study period.

We hope that our observations will serve as a foundation for further research on colonoscopy quality outcomes when performed under conditions of heightened PPE requirements. More robust study designs using propensity matching or historical control populations with a larger sample size can be conducted to evaluate the impact of EPPE on established colonoscopy quality indices such as ADR and PDR. 


\section{Conclusion}

The COVID-19 pandemic has resulted in heightened PPE requirements during endoscopic procedures. Our study suggests that the task of performing a colonoscopy is not negatively affected by EPPE. Colonoscopy can continue to be safely and effectively performed with use of EPPE.

\section{Competing interests}

The authors declare that they have no conflict of interest.

\section{References}

[1] Repici A, Maselli R, Colombo M et al. Coronavirus (COVID-19) outbreak: what the department of endoscopy should know. Gastrointest Endosc 2020: doi:10.1016/j.gie.2020.03.019 [Epub ahead of print]

[2] Soetikno R, Teoh AY, Kaltenbach T et al. Considerations in performing endoscopy during the COVID-19 pandemic. Gastrointest Endosc 2020: doi:10.1016/j.gie.2020.03.3758 [Epub ahead of print]

[3] British Society of Gastroenterology. BSG/JAG COVID-19 guidance and advice. Available at (Accessed March 27, 2020): https://www.bsg.org. uk/covid-19-advice

[4] American Society for Gastrointestinal Endoscopy. Joint Gl society message: COVID-19 clinical insights for our community of gastroenterologists and gastroenterology care providers. Available from (Accessed March 27, 2020): https://www.asge.org/home/joint-gisociety-message-covid-19
[5] Chiu PWY, Ng SC, Inoue $\mathrm{H}$ et al. Practice of endoscopy during COVID19 pandemic: position statements of the Asian Pacific Society for Digestive Endoscopy (APSDE-COVID statements). Gut 2020: doi:10.1136/gutjnl-2020-321185 [Epub ahead of print]

[6] Ang TL, Li JW, Vu CK et al. Chapter of Gastroenterologists professional guidance on risk mitigation for gastrointestinal endoscopy during COVID-19 pandemic in Singapore. Singapore Med J 2020: doi:10.11622/smedj.2020050 [Epub ahead of print]

[7] van Doremalen N, Bushmaker T, Morris DH et al. Aerosol and surface stability of SARS-CoV-2 as Compared with SARS-CoV-1. N Engl J Med 2020: doi:10.1056/NEJMc2004973 [Epub ahead of print]

[8] Johnston ER, Habib-Bein N, Dueker JM et al. Risk of bacterial exposure to the endoscopist's face during endoscopy. Gastrointest Endosc 2019; 89: 818-824

[9] Wong SH, Lui RN, Sung J]. Covid-19 and the digestive system. J Gastroenterol Hepatol 2020: doi:10.1111/jgh.15047 [Epub ahead of print]

[10] Kim TH, Kim CH, Shin SD et al. Influence of personal protective equipment on the performance of life-saving interventions by emergency medical service personnel. SIMULATION 2016; 92: 893-898

[11] Johnson AT. Respirator masks protect health but impact performance: a review. J Biol Eng 2016; 10: 4

[12] Palmiero AJ, Symons D, Morgan JW et al. Speech intelligibility assessment of protective facemasks and air-purifying respirators. J Occup Environ Hyg 2016; 13: 960-968

[13] Roberge RJ. Face shields for infection control: A review. J Occup Environ Hyg 2016; 13: 235-242

[14] Waye JD. Difficult colonoscopy. Gastroenterol Hepatol 2013; 9: 676678 
- Supplementary Table 1 Results stratified according to trainee involvement.

\begin{tabular}{|c|c|c|c|}
\hline Variables & 2019 (SPPE) & 2020 (EPPE) & $P$ value \\
\hline Total number of colonoscopies ( $\mathrm{n}, \%$ ) & $116(47.0)$ & $131(53.0)$ & \\
\hline Experienced endoscopist & $95(81.9)$ & $106(80.9)$ & 0.843 \\
\hline Trainee & $21(18.1)$ & $25(19.1)$ & \\
\hline Adenoma detection (n, \%) & $25(21.6)$ & $39(29.8)$ & 0.141 \\
\hline Experienced endoscopist & $19(20.0)$ & $33(31.1)$ & 0.072 \\
\hline Trainee & $6(33.3)$ & $5(25.0)$ & 0.572 \\
\hline Polyp detection (n, \%) & $47(40.5)$ & $66(50.4)$ & 0.120 \\
\hline Experienced endoscopist & $32(33.7)$ & $55(51.9)$ & 0.009 \\
\hline Trainee & $13(72.2)$ & $10(50.0)$ & 0.162 \\
\hline Cecal intubation (n, \%) & $116(100)$ & $130(99.2)$ & 0.346 \\
\hline Experienced endoscopist & $95(100)$ & $106(100)$ & \\
\hline Trainee & $18(100)$ & $19(95.0)$ & 0.336 \\
\hline Time to cecum (min) & $10.0(8.0-16.5)$ & $10.0(7.0-15.0)$ & 0.524 \\
\hline Experienced endoscopist & $10.0(7.0-15.0)$ & $10.0(7.0-13.0)$ & 0.527 \\
\hline Trainee & $16.0(10.0-20.0)$ & $15.0(11.0-18.5)$ & 0.638 \\
\hline Withdrawal time (min) & $10.0(8.0-16.5)$ & $10.0(10.0-18.0)$ & 0.288 \\
\hline Experienced endoscopist & $10.0(8.0-15.0)$ & $10.0(9.0-14.0)$ & 0.517 \\
\hline Trainee & $14.5(10.0-25.0)$ & $19.5(15.5-28.5)$ & 0.177 \\
\hline Total procedure time ( $\mathrm{min}$ ) & $22.5(20.0-34.5)$ & $23.0(18.0-35.0)$ & 0.946 \\
\hline Experienced endoscopist & $21.0(18.0-30.0)$ & $20.0(17.0-31.0)$ & 0.639 \\
\hline Trainee & $34.5(20.0-49.0)$ & $34.0(30.5-43.0)$ & 0.473 \\
\hline
\end{tabular}

